\title{
Tendencies in Women's Painting in Kazakhstan in the Context of Self-Identification
}

Dilyara Safargaliyevna Sharipova, ${ }^{\dagger}$ Aigerim Tursynovna Yespenova, ${ }^{\dagger}$ Svetlana Zhumasultanovna Kobzhanova ${ }^{\complement}$ and Raikhan Abdeshevna Yergaliyeva ${ }^{\dagger}$

\section{Abstract}

This paper examines the phenomenon of women's pictorial art in Kazakhstan of the XX century. The analysis of the works by many authors (Maria Lizogub, Zeinep Tusipova, Almagul Ikhanova, Anzhelika Akilbekova) allows researchers to describe the specific nature of Kazakh women's painting. Analysing the personality of artists, their creative path, the authors reveal the style of the works and its importance for the development of particular art areas. Female artists overcame the barriers of social inequality declaring themselves as the leading representatives in the art and culture of Kazakhstan. At the same time, making an accent on the woman's substantial spiritual potential, they comprehended her as a keeper of hearth and home and the patriarchal way of life. This duality consists in the identification processes when the representation of female interacted with ethnic and cultural self-determination.

Keywords: Women's Painting, Arts and Crafts, National Traditions, Ethnocultural Identification, Gender Aspects, The Socio-Cultural Situation, Kazakhstan

\footnotetext{
${ }^{+}$Department of Fine Arts of Institute of Literature and Art named after M. Auezov of the Science Committee of the Ministry of Education and Science of Kazakhstan, Kurmangazy str.29, 050010, Almaty

${ }^{*}$ Corresponding Author, Email: dilyara_s_sharipova@mail.ru

IT The A. Kasteyev State Museum of Arts of the Republic of Kazakhstan, Koktem-3 microdistrict, 22/1,050040, Almaty (C) 2018 Sharipova et al. This is an Open Access article distributed under the terms of the Creative Commons Attribution License (http://creativecommons.org/licenses/by/2.0), which permits unrestricted use, distribution, and reproduction in any medium, provided the original work is properly cited.
} 


\section{Introduction}

In comparison with the other regions of Central Asia, the active and numerous presence of female artists at different stages of development of the fine arts in Kazakhstan urgently requires scientific research and comprehension. This paper reviews the women's pictorial art in Kazakhstan in the aspect of gender studies.

Joan Scott writes about four aspects of gendered relationships in the society through which one can conduct a full historical analysis: first, culturally-available symbols that define the mental background of human activity; second, normative concepts based on symbolic meanings that are expressed in religious, educational and political doctrines; third, social institutions (from family-related to the state ones), and fourth, gender subjective identity (Scott, 1986, p. 67-68).

Subjective gender identity, in our view, defines the female painting. The same processes take place in literature. Irina Savkina writes: "[t]he most interesting thing in women's literature is that only there and nowhere else the image of a woman, a feminine beginning, has been seen, thought out and created by a woman herself" (Savkina, 1997, p. 359).

In this research, we consider the issues related to gender and ethnocultural identification of female artists and the central tendencies in women's art in the Kazakh school of painting between the 1930s and 2010s. Among the diverse artistic practices, the artworks have been chosen by female artists who are deemed as the real pearls of their generation. These are Maria Lizogub (1909-1998), who refers to the first professional artists in Kazakhstan; Zeinep Tusipova (b.1948), who was a leading representative of the generation of the 1970s and 1980s; and Almagul Ikhanova (b.1970), Anzhelika Akilbekova (b.1970) are representatives of the new female movement in independent Kazakhstan. All of them led active public and cultural activity: Maria Lizogub and Zeinep Tusipova in different years were the members of the Board of the Union of Artists of the Republic of Kazakhstan, while
Anzhelika Akilbekova currently is a Deputy Director at the Kasteyev State Museum of Arts of the Republic of Kazakhstan. The emphasis on women's creativity makes it possible to reveal the general socio-cultural situation in the reviewed period of Kazakh art development. "The basis for the methodology of gender research," Olga Voronina writes, "is not just a description of differences in the statuses, roles and other aspects in the life of men and women, but the analysis of power and domination asserted in the society through gender roles and relationships" (Voronina, 2001, p. 105-106).

Of particular importance will be representations of gender within socialist realism and changing attitudes among female artists toward this dominant artistic style of the Soviet period (Golomshtok, 1994). Female artists lost their positions within the hierarchy of the Union of Artists, in part compelling them to find new guidelines for their practices. Thus, art created by women artists in Kazakhstan entailed a particular way of resolving the issue of gender in a concrete socio-cultural situation.

The work consists of three parts - the first part considers the attitude to creativity, the central themes and motives in the painting of female artists in the era of the Stalin period. The second one - the representation of female images during the period of rejection of Soviet dogma and principles in the course of searching for the national identity during the 1970s and 1980s. The third part analyses the features of the modern transformation of female painting in the direction of a sexually liberated female image.

The article begins with a description of the methods. Following this, we paint the subject of analysis in our results and discussion section.

\section{Methods}

The methods of this research have been dictated by the objectives and character of the subject of analysis. To analyse the creative work of female artists, along with the necessary historical and problematic approach, we have also considered the practitioners as they work 
within social, cultural, and gendered spheres. Thus, the methods of formal and stylistic and motivational analysis are based on the study of the specificity of the artistic solution of specific works and the way of artistic and cultural interpretation, which makes it possible to identify the main trends in the development of Kazakh art. This, in turn, helped us to trace the origin of gender representation forms in the historical event under the changes in the social and political life of Kazakhstan from the totalitarian period to independence in 1991. Our research has also taken into account the findings of gendered-led analyses of women's prose in literary criticism.

In 1731 the Kazakh lands were annexed by Russia and for many years remained the underdeveloped agrarian outskirts of the Russian Empire. The Socialist Revolution of 1917 gave a powerful impetus to the modernisation of the region. The industrial development of Kazakhstan in 1926-1940 transformed it from an agrarian country into an industrial-agrarian republic of the USSR. This process is characterised by the growth of cities and the urban population. The 1920s were the period of the professional art formation, the development of cultural institutions: theatres, art galleries, publishing houses, as well as the creation of artistic unions of writers, composers and artists, and first educational institutions for training artistic intelligentsia.

\section{Results and Discussion}

Maria Lizogub was born in Ukraine. In the Soviet period, it becomes possible that a young single woman decides to journey from Europe to Asia on her own. When M.Lizogub was finishing her studies, she learned about the Kazakh poet-akyn Zhambyl. She became interested in his biography and poems. Kazakhstan was a desolate Asian outskirt of the former Russian Empire. One could get there only from the capital of the USSR - Moscow after travelling by train for ten days. She did not have any acquaintances. However, her curiosity and lust for impressions gave an impetus to the fact that a young European woman, alone, went to the Asian city, which was $1000 \mathrm{~km}$ away from her home. Her arrival in Kazakhstan can be referred to as the significant evidence of a woman's new selfsentiment in the Soviet state. The materials collected on this trip became the basis for her excellent diploma thesis. In 1940, Lizogub moved to Kazakhstan permanently.

As a person of her time, Maria Lizogub organically absorbed and then reflected in her art all social doctrines and mythologemes. In the USSR, it was impossible to professionally engage in the art without a membership in the corresponding artistic union. The Union of Artists made it possible to earn money on the orders for the creation of topical paintings on the themes like establishing Soviet power in Kazakhstan, the construction of socialism, the working days of the republic, portraits of famous workers and farmers, officials, technical and artistic intelligentsia. To be a part of the Soviet system and realise themselves as professional artists, they had to strictly follow the norms and directives of the authorities related to art as the conductor of Soviet ideology.

In practice, women were alienated from politics and power while having formal legal equality. The Union of Artists of Kazakhstan, for example, has never been chaired by a woman, though there were women in the managing board. Julia Penelope has developed a theory of the patriarchal universe of discourse (Penelope, 1990). The conceptual meaning of this theory is that a woman is compelled to define and express herself with a language that embodies a male view of the world. To get a job - for painting - a woman artist, had to choose not the topics that inspired and excited them but to voice ideological doctrines that strengthened the existing imperious system in which men dominated. When she painted pictures of Stalin as a caring father and heroes of the Second World War as his sons, she reproduced this patriarchal scheme of socialist realism.

The external side of the totalitarian regime, the splendours and romance of this era gave birth to Lizogub's bright works glorifying Stalin, 
socialist transformations and the war against illiteracy. The latter point was the subject matter of her first work, "Pioneer-Agitator in the Village" (1940), painted by her immediately upon arrival in Kazakhstan and portraying a little girl teaching elderly women. The usual social hierarchy was turned on its head. In the society of nomads, the elders, aksakals, had a great experience which was transferred to the young (Argynbaev, 1996, p. 37). At the same time, despite the realistic socialist pictures of the new life overthrowing the old Kazakh way of life they proved to be a necessary element for Lizogub to convey her understanding of the new homeland.

The real nature of Lizogub was revealed in paintings of the themes that excited her. First, she had a great interest in Kazakh arts and handicrafts. Besides, she was always interested in the mysteries of the creative process and produced many portraits of actors and writers. However, the most famous psychological portraits were those of female artists and women who themselves were devoted to art.

As far back as the early 1940s, at the discussions of the exhibitions, it was stressed that Maria Lizogub was the only artist to appeal to the Kazakh theme. One of the excellent examples of her deep understanding of pictorial folklore was the "Folk Master" of 1960, depicting a woman close to her regarding profession and spirit: Latifa Khodzhikova, the first Kazakh artist of theatrical costumes and a talented craftswoman. This work, as well as the "Portrait of the Painter Kovalevskaya" (1953), became the culmination of this genre in the art of Lizogub. As models, she chose successful women, who reached high points in their careers and tried to solve the mystery and an unusual turn of their talent. Both heroines are depicted at the peak of their creative inspiration. It seems that only one step separates them from understanding the truth of creativity: one moment and the idea cherished in their mind will appear before them as a bright comprehensive picture down to every detail. However, the artists approached this state differently. Zoya Kovalevskaya, the
People's Artist of Uzbekistan, is internally prepared for a decisive attack to win a longstanding dispute with nature and to reflect the real life to a high degree of accuracy and pressure. Firmly grasping the instruments, she directs her cold and sharp look into a distance ready at the right time to make a decisive brushstroke. The warriors can envy the artist's discipline and the power of spirit. Meanwhile, Latifa Khodzhikova meets inspiration as good news, as calm happiness finding her suddenly and taken as a long-awaited gift. She as if basking in the rays of this divine gift.

These portraits have less than a decade gap, but surprising is the difference in style preferences and understanding of the nature of creativity! In the picture of L. Khodzhikova, it is shown that female creativity is not only the rational construction of the form but also an intuitive process when the complete artistic image is formed in mind all of a sudden - at a lightbulb moment. From hard lines, fine details and mirror reflections developing the Serov line of the Russian portrait art to the impressionistic vision, the continuous display of the overall beauty of folk art and the mystery of the gift of the ordinary Kazakh craftswoman. In contrast to Kovalevskaya, for Lizogub the Kazakh woman-creator is not a participant in the dramatic struggle with an inactive form, as felt by many famous male artists, but a harmonious successor of age-old traditions, the keeper of hearth and home.

The success of these paintings is that Lizogub has revealed ingenious women are having an unshakable feeling of endless power over the form and the ability to exercise their inexhaustible creative ideas. This heartfelt message in the mid-XX century was a real breakthrough in comprehending the creative freedom of women. The question stated by Linda Nochlin - why there were no great female artists - has revealed the role of institutions in shaping artistic practices (Nochlin, 1971). In the Soviet Union, especially in the mid-XX century, it was asserted that a woman is and must become a Creator. However, the reality of life, working conditions, 
and the patriarchal worldview preserved in Kazakhstan pushed women artists into the background. The well-paid orders of the Union of Artists to produce large-scale paintings on the theme of socialist realism were never commissioned for women. So, the gap between slogans and life forced women artists to find their niche.

Lizogub defined the range of plots related to home and Kazakh folk art as an inseparable part of hearth and home which later was developed by other artists. Under the high willingness to record all new, that happened in socialist Kazakhstan, of importance for Lizogub was the motif of the steadfastness of the traditional mode of life. In the 1960s she often placed her characters in the interior of the Kazakh yurt, showing the house as a temple, as a sacred place. So, the motif of home united the whole old way of life as an absolute ideal and basis for continuity and tradition.

The glorification of home and the woman as its anchor was continued at the new stage by Zeinekul Tusipova. In contrast to Lizogub's paintings, Tusipova puts everyday women's labour rather than the creative activity in the forefront of her work which has become the primary source of the artist's inspiration. The strong personality of Tusipova, her active position and freedom traditionally inherent to Kazakh women, resulted from a somewhat ambiguous role of women in the nomadic way of life. One can remember the female warriors in Kazakh folk tales and legends, the heroines of epic poetry of the nomadic people, bold and free in their choice. The images of women in epic poetry and, broadly understanding, in the life of the nomadic people - bold, intelligent, decisive and even reckless in feeling the freedom of life choice - are embodied temperamentally with her brush.

Tusipova's bright impulsivity, which is more typical for the Europeans rather than for the Kazakhs, reveals her strong temperament which imparts a sincere feeling to any object within her field of vision. The natural force of being, even excess of it, appear in her still lives to fill them with energy.
The redundancy of creative and human energy, the ability with the most significant interest and sincere warmth to perceive what is happening and to transfer her feelings on canvases are also demonstrated in a specific spontaneity of the creative process itself. She paints rapidly, as if effortlessly not fearing the simplicity and pure ordinariness of plots, simplicity of features of recognisable persons, places and objects finding in them an opportunity to express her love to this familiar world.

The life of the Kazakh village, aul, is a leitmotif of Tusipova's creative work to which she has devoted many years. This continually growing and practically endless series includes genre paintings and landscapes executed with great freedom and variety. Complementing each other, as a result, they create a confident, wise and touching, straightforward, and at the same time, picturesque symphony. Her genre pictures with the poetic rendering of the beauty of the people and the traditional mode of life, the charm and grandeur of nature, being lyrical, are nevertheless perceived as monumental.

The Kazakh steppe in her artworks is a simple native home, but it is also the great unknown beauty and mystery of nature. The atmosphere of infinite trust and love for common and straightforward manifestations of life reigns in them. The beauty of mountains and foothills, the richness and uniqueness of our motherland is rendered with a piercing feeling of their hourly ordinariness. This becomes an unformulated principle of inescapability and even inevitability of the manifestation of beauty in everyday life and expresses the artist's impression of delight and admiration and the ability to sense and contemplate greatness in small things.

Very emotionally she portrays the people and nature of Kazakhstan. Expressive and full of significant power is her character; full of quiet inner dignity and beauty are her women engaged in daily household chores: they are boiling meat, frying baursaks (fried doughs), or looking after a small flock of sheep crowded in 
the courtyard near cob walls. All these scenes are painted with the unique poetry of everyday life. Commonness appears in them as eternal and peaceful, joyful and sad. Human life hidden in these cosy or abandoned courtyards either scares one by its homelessness or attracts by the resistance to the hardships of life. Ultimately, this leads to the thought about the everlasting beauty and happiness of existence, about the fragile beauty of even the most ordinary moments of human life. Selfsufficiency as a principle of traditional being penetrates the lives and consciousness of Tusipova's characters. Altogether this creates an atmosphere of the people's faith in the triumph of normal and eternal values.

Tusipova represents female subjectivity not connected with the values and norms of male topology as the essential element of the world order. The ideological basis of harmony, confidence in future and the inner peace of her characters are rooted in the persuasive power of national ideals professed by the artist.

As Keti Chukhrov noted, "with reason, many researchers point out that the category of "sex" has been of lower significance with post-Soviet culture than in the West. Biology provides the basis for the anatomical predestination of a man. Human beings are anatomically divided into women and men, whereas "gender" is a cultural identification, or social identification" (Fanailova, 2009).

Almagul Ikhanova actively uses the symbols of the ancient Turkic people by rethinking the nomadic past and reflecting the world outlook of primordial people. Her art pieces are characterised by the mixture of oriental knowledge and original use of techniques allowing her to outline by texture the significant parts of her compositions. Threedimensional sign symbols acquire additional attractiveness and affect the artistic interpretation of her pictures each of which conveys a deeper meaning. Behind the external decorativeness, it is hidden the universal truth of symbols and signs. The strength and power of argali or beast-fighting scenes are projected on the realities of the present time evoking specific associations among the viewers.

As a bright example of searches of a modern woman-creator is the art of Angelika Akylbekova who employs various media and is actively mastering the art schools of different epochs. There are some of her works that are signed as "Anzhelika Urazbekova". Here sounds the difference in the perception of own self. For her, of importance is to state about her feelings rather than to remain in history.

The subject matter of her works and their manner of execution are strikingly varied. Modern life, ancient history, fragments of nature, realistic depiction and stylisation, impasto painting and beautiful glazes, an abundance of techniques, plots and transformations - all that is fused in a single creative impulse. An imaginative, creative fusion is achieved through the application of conditional elements and real fragments, colours and lines.

It is important to note that all artworks by Akylbekova contain ornamental motifs placed on the surface for the sake of more movement in the space, designation of symbolic of action and preservation of the national code. The interior objects taken from life are becoming independent objects of admiration. Household items at the same time are perceived as symbols, protectors, decorative elements, etc.

The most interesting is the artist's experiments with nude figures. The researcher Oksana Sarkisyan argues that the first sign of the gender-oriented art in the Soviet and postSoviet space has become "the actualisation of sensuous as an alternative to Soviet androgyny" (Sarkisyan, 2010, p. 77). The effect of interpreting the achievements of the world art on the matter of own consciousness and vision of nude figures is achieved through the original manner of execution based on design principles of modernist trends where the composition of a sheet is physically materialised in original "imprints" and exciting poses of models. The artist shows complete mastery in handling the space and detailed 
study of naked bodies under the beautiful black and white planes.

At first glance, it seems that these are accidentally taken fragments of reality. Her graphic nudes are as if produced in one breath. However, everything is carefully thought out: the precise composition, strict lines and attention to distinctness. Her female characters are reliable and naturalistic, and apparent simplicity in rendering nudes creates an impression of a watched life. According to the artist, she is attracted by the beauty of a woman, by the movement and strength of her body. The main point in creativity is the task of self-representation of female ego. Her things and belongings look like a reflection of everyday women's concerns and thoughts, as a form of autobiography. As Elizabeth Miller noted, "the traditional concept of autobiography is changing to the concept of autogyno-graphy - with the assertion of specific female subjectivity in the autobiographical writing" (Wilson, 1982, p.53).

In this case, various techniques by Akilbekova produce those type of women's writing (l'ecriture feminine) which Helene Cixous determined as a method through which a woman gets an opportunity for self-expression. According to Cixous, the sources of women's writing are "the female body and female sexuality". Therefore, women's writing, like the eroticism of a woman, is "open and multiple", "variable and rhythmical", "full of pleasures and opportunities" (Cixous, 1976, p.882).

\section{Conclusion}

In conclusion, it should be stressed that at the stage of formation of Kazakh fine arts (the 1930s-1950s), women's painting was developed with the artists' self-awareness being the main theme. With the example of Maria Lizogub, it was demonstrated that female artists overcame the barriers of social inequality declaring themselves as the leading representatives in the art and culture of Kazakhstan. At the same time, making an accent on the woman's huge spiritual potential, they comprehended her as the keeper of hearth and home and the patriarchal way of life. This duality consists in the issue of identification processes when the representation of female interacted with ethnic and cultural self-determination. Especially evident it was displayed in the generation of the artists of the 1970s-1980s who asserted their own ethnic and cultural identity. Zeinep Tusipova declaratively announced a Kazakh woman as an anchor of the national traditional culture and values which the Soviet colonial machinery tried to destroy. With high excellency and a sincere expression of emotion, she recreated the original beauty and power of ancient traditions and the traditional mode of Kazakh life by depicting the unique national culture of the Kazakhs. The artists of modern Kazakhstan continue the traditions of women's painting by preserving a considerable interest in the history and symbols of their nation. Almagul Ikhanova, for example, produces panels made of leather where these symbols acquire sculptural tactile sensation and physicality. For Kazakh women artists, the connection of handmade with visual is essential.

Meantime, cruel experiments and willingness to convey the diversity of their inner world lead the artists to the representation of physicality. Anzhelika Akilbekova, appealing to the theme of the female body, tries to touch a private sphere and show many shades of intimate feelings rather than to render the declaratively stated social themes. The subjective identity of a creative person includes ethnocultural identity expressed and represented in creative work. "Women's writing is not any text written by a woman, but a gendered phenomenon involving depersonalization as a specific women's ability to open themselves to other" (Pakhsarian, 2010, p. 87).

At each stage of development of Kazakhstan's painterly school, the female artists solved the issues of personal and national self-affirmation. Public resonance of their art was as crucial as the embodiment of own emotional experiences and representation of corporeity. The identified features of women's art in Kazakhstan reflect the general social and cultural situation 
connected with multidirectional poles. These include the duality of the status of women in the family and the country's public life, the diffusion of national identity in the Soviet empire and its passionate assertion by the creative intelligentsia, protection of the traditional mode of life and building of the industrial and then, post-industrial society.

The harmonious unity of modernity and tradition, the compelling, emotional experience of everyday things, nature and life, are the main characteristics of women's art in Kazakhstan.

\section{References}

Argynbaev, Kh.A. (1996). Kazakh family. Almaty: Kaynar.

Cixous, H. (1976). The laugh of the Medusa, Signs, 1(4), 875- 893.

Fanailova E. (2009, April 25). Women's art as a project of the future. Speech in the program "Freedom in clubs". Date viewed 24.07.2017. Retrievedfrom www.svoboda.org/a/1615853.html.

Golomshtok, I. (1994). Totalitarian art. Moscow: Galart.

Nochlin, L. (1971). Why have there been no great women artists? Art News, 69(9), 22-39, 67-71.
Pakhsarian, N. (2010). "The Second Sex" by Simone de Beauvoir and the fate of feminism in modern French literature. In N. Pakhsarian, E.V. Sokolova, E.A. Tsurganova, A.A. Revyakina (eds.). Gender issues in modern literature. ISISS RAN. 217.

Penelope, J. (1990). Speaking Freely: Unlearning the lies of the fathers' tongues. Oxford: Pergamon Press, 281.

Sarkisyan, O. (2010). Gender on the Russian art scene. In N. Kamenetskaya (ed.). Zen d'art (ed.). Gender history of art in the post-Soviet space: 1989-2009. MMOMA, 77-85.

Savkina, I. (1997). Who and how writes women's literature. New Literary Observer, 24, 359-372.

Scott, J. W. (1986). Gender: A Useful Category of Historical Analysis. The American Historical Review, 91(5), 1053-1075.

Voronina, O. (2001). Theoretical and methodological grounds for gender research. In Theory and methodology of gender research. A course of lectures. Moscow center for gender studies. 13-106.

Wilson, E. (1982). Minor Writing an Autobiography. London: Virago Press Ltd. 